\title{
Lenin: teoria e prática revolucionária, organizado por Marcos del Roio, Anderson Deo e Antonio Carlos Mazzeo
}

[DEL ROIO, Marcos; DEO, Anderson; MAZZEO, Antonio Carlos (orgs.). Lenin: teoria e prática revolucionária. Marilia: Oficina Universitária; São Paulo: Cultura Acadêmica, 2015, 418 p.]

\section{Pedro Pompeo Pistelli Ferreira ${ }^{1}$}

A figura de Vladimir Lenin, enquanto revolucionário e teórico marxista, é portadora de um peculiar paradoxo: por um lado, poucos legados teóricos tiveram tanta relevância histórica, uma vez que suas reflexões foram tomadas como base para várias revoluções efetuadas ao redor de todo o globo terrestre; por outro, sua obra deixa de ser estudada nos grandes centros universitários, ou, quando o é, estudam-na de maneira dogmática e ossificada - seja em uma retórica celebratória, seja condenatória -, de modo a torná-la inócua para os tempos contemporâneos.

Frente a esse cenário, parece-nos importante comentar um ponto fora da curva dessa tendência: o livro Lenin: teoria e prática revolucionária, gestado a partir dos debates do VI Seminário Internacional Teoria Política do Socialismo - Lenin 90 anos depois: política, filosofia e revolução e publicado pelas editoras Oficina Universitária e Cultura

1 Pedro Pompeo Pistelli Ferreira, graduado em direito pela Universidade Federal do Paraná (UFPR), onde foi participante do programa de Iniciação Científica - Voluntária, organizado pela Pró-Reitoria de Pesquisa e Pós-Gradução (PRPPG) da UFPR. 
Acadêmica. Tal obra, editada por ocasião do nonagésimo aniversário da morte do revolucionário russo, traz uma perspectiva crítica e criativa do legado lenineano. Para tanto, Lenin é apresentado como um "líder político avesso a aplicar prescrições - que precisamente possuíam estatuto de lei para a doutrina marxista - e preocupado, ao contrário, em examinar minuciosamente as circunstâncias históricas com as quais se faz urgente enfrentar." (p. 14). Em toda a publicação, malgrado a grande variedade de autores e de temas, percebemos uma preocupação em frisar o radical antiesquematismo lenineano e a sua profunda negação de qualquer postura meramente contemplativa da realidade. Resgata-se, incisiva e instigantemente, não um Lenin enquanto líder genial do proletariado que teria formulado a doutrina científica de interpretação da sociedade (o marxismo-leninismo), mas sim o Lenin enquanto teórico e prático revolucionário que nunca se esqueceu de afirmar que "a essência mesma, a alma viva do marxismo é a análise concreta da situação concreta” (LENIN, 1980, p. 136, tradução nossa).

Podemos perceber a presença dessa interpretação em todas as seções da obra: tanto no prefácio de Miguel Vedda quanto nas três partes que dividem as contribuições em relação a seus temas. Na primeira, pode-se identificar uma compilação de artigos voltados a compreender o significado político e organizacional da teoria de Lenin, em especial a sua teoria do partido e do desenvolvimento da consciência de classe dos oprimidos. Como exemplo dos artigos dessa parte, Antonio Carlos Mazzeo vê na teoria e prática de Lenin a concepção de "uma educação em constante movimento" na qual se entrelaçam "a experiência e a consciência do operário" (p. 31 e 44), de modo a colocar o partido revolucionário como espaço de mediação entre esses dois âmbitos. Com essa interpretação, consegue-se superar uma visão distorcida da ideia do partido em Lenin, que deixa de assumir o papel de vanguarda inconteste e infalível da massa operária, para, então, adotar um aspecto notadamente antidogmático e mais próximo das verdadeiras intenções do revolucionário russo.

Na segunda parte, temos uma compilação de artigos que abordam a contribuição do pensamento de Lenin para diversas áreas: sobre literatura e a política cultural do governo proletário, as divergências 
de pensamento entre Lenin e Trotsky, as críticas de Lenin ao chauvinismo, a crítica da economia política e, em um tema que muito nos apetece - o que justificará nossa mais detida incursão nos argumentos do texto -, a questão do direito em Lenin.

Neste último artigo, de autoria de Jair Pinheiro, realiza-se um cotejo entre "o conceito liberal de direito e as contribuições de Lênin" ( $p$. 224). Para tanto, efetua-se uma "leitura formal-normativa" das manifestações do revolucionário russo, na qual se pretende, em especial, compreender como Lenin trata a formação/interpretação das normas, que são, de acordo com a tradição liberal, concebidas como jurídicas - mesmo que o próprio Lenin não tenha expressamente classificado tais normas como direito. Ora, essa opção heurística de pensar a relação de Lenin com o direito parece-nos profícua na medida em que permite pensar dinamicamente sobre o fenômeno jurídico, sem ter que perscrutar cansativamente as convicções pessoais do líder bolchevique sobre o conceito de direito. No entanto, a escolha da tradição kelseniana para compreender o que é direito soa-nos, em alguma medida, menos compatível com o espírito da obra lenineana do que, por exemplo, a tradição da crítica jurídica soviética (em especial, Stutchka e Pachukanis). Mesmo com tais ressalvas, deve-se indicar que Pinheiro faz uma importante revisão bibliográfica que acaba por demonstrar a relevância dada por Lenin a uma nova forma de ler e ver as normas e leis aplicadas pelo governo soviético, bem como a distribuição de direitos e obrigações. Especialmente instigantes nos parecem suas considerações sobre a reconfiguração que Lenin faz do sujeito de direito, que passa a se pautar no produtor direto, no trabalhador, enquanto agente criador e declarante de direito dentro de uma realidade essencialmente concreta, o que permite subverter a abstração clássica do sujeito de direito capitalista (p. 229-232) - algo que, ao nosso ver, culmina na necessidade de ferir de morte a forma jurídica em si mesma, que não se caracteriza por estabelecer um dever-ser (como defende Pinheiro [p. 240-241]), mas sim por reproduzir a abstração dos sujeitos que trocam equivalências.

Por fim, na terceira parte, temos reflexões voltadas principalmente à influência/recepção do pensamento de Lenin em diversos autores - a 
exceção é o artigo de Gianni Fresu, destinado a refutar a tese segundo a qual Lenin seria um intelectual dogmático e doutrinário. No caso, Lenin é abordado em diálogo com teóricos como José Carlos Mariátegui, Carl Von Clausewitz, Antonio Gramsci e György Lukács. Como exemplar, indicamos o artigo Mariátegui e a tradução latino-americana do leninismo, de Leandro Galastri. Nele, o autor explicita os pontos de contato entre o peruano e Lenin, em um claro indicativo de que o aspecto criativo e criador do marxismo Mariátegui, em boa medida, deve-se "também a aproximações do pensador peruano com as reflexões e desenvolvimentos do marxismo 'ortodoxo' levados a efeito por Lênin" (p. 281). Esse aspecto nos leva a questionar as interpretações que, refutando peremptoriamente o legado lenineano, classificam-no como uma perspectiva eurocêntrica de mundo, que não poderia ajudar a frutificar reflexões intelectuais realmente libertadoras para a realidade da América Latina. Assim, pode-se perceber a validade de uma leitura criativa da obra de Lenin para nos ajudar a efetivar a "necessária e dialética tradução dos princípios do materialismo histórico para as lutas proletárias e camponesas latino-americanas" (p. 296-297), tal como Mariátegui efetivou em seu tempo.

Conquanto a grande pertinência e vitalidade das reflexões inscritas na obra sejam inegáveis, elas padecem de uma insuficiência: a completa ausência de diálogo com a nova historiografia que, em especial nos Estados Unidos - centro por excelência dos estudos (anti)soviéticos -, tem passado a questionar, a partir dos instrumentais da história social, as limitações da historiografia gestada pelo início da Guerra Fria, que era voltada praticamente à elaboração de propaganda negativa da Revolução de Outubro (SEGRILLO, 2010). São deixados de lado tanto autores inovadores que mantém uma avaliação negativa do legado de Lenin (como Orlando Figes ou Reginald Zelnik), quanto autores mais elogiosos do papel lenineano na história, seja desde uma perspectiva acadêmica (Lars T. Lih) ou mesmo politicamente vinculada ao marxismo e ao socialismo (Paul Le Blanc e August H. Nimtz).

Ora, as consequências da ausência desse debate são explicáveis a partir dos próprios argumentos da obra como um todo: se reconhecemos que Lenin, antidogmaticamente, faz análises concretas de 
situações concretas, para compreender seus textos é necessária a mais rigorosa reconstrução do contexto no qual eles foram escritos. Para tanto, a pesquisa historiográfica, em todas as suas minúcias, deve ser o mais precisa possível. Sem ela, estaremos fadados a debater anacronicamente as ideias de Lenin e, então, seremos incapazes de apreender radicalmente o seu método de cognição e de intervenção na realidade.

Provavelmente, o melhor exemplo disso podemos tirar da repercussão da obra de Lars Lih (2008) denominada Lenin rediscovered: What is to be Done? in context. Nela, Lih questiona as interpretações que, ossificando dois trechos do panfleto Que fazer? de Lenin - os quais são cunhados com o epíteto de "passagens escandalosas" -, atribuem ao editor do Iskra uma visão elitista da transformação social e eminentemente pessimista sobre a capacidade dos operários de assumirem sua consciência de classe sem a liderança paternalista de intelectuais externos à classe operária. Após analisar todos os escritos de Lenin do período e as manifestações político-teóricas de seus interlocutores, Lih identificou que, na verdade, a perspectiva de Lenin era a mais otimista sobre a capacidade do proletariado atingir a consciência de classe sem a intervenção de intelectuais. Além disso, as duas passagens que justificariam as interpretações de um Lenin intelectualista e elitista seriam na verdade uma conjunção de erros de tradução (em especial, a tradução do termo стихийный [stikhiynnyi] por espontâneo, o que dá uma conotação positiva a um vocábulo que, em russo, tem um significado predominantemente negativo, como indicação de descontrole, de falta de consciência e de fatalidade) e erros de expressão de Lenin, que tentava mimetizar o vocabulário adotado por seus adversários (LIH, 2008, p. 613-670).

Na verdade, os próprios autores do jornal Rabotchee Delo, principal adversário teórico do Iskra dentro da socialdemocracia russa, acreditavam que a "tarefa essencial da social-democracia" consistia no "desenvolvimento da consciência de classe do proletariado" e, principalmente para o caso russo, na "aceleração da transição do movimento espontâneo [стихийный, stikhiynnyi] de massas para o movimento consciente de classe" (KRITCHEVSKIY, p. 2, tradução nossa). 
Portanto, a questão de fundo na polêmica com esse grupo fundava-se justamente na avaliação: a classe trabalhadora está pronta para agir de forma ativa e independente na luta política? A resposta de Lenin era um enfático sim.

Destarte, essas descobertas nos trazem um novo elemento na interpretação do debate sobre a organização do partido em 1902: Lenin não apenas defendeu a reorganização do POSDR da forma que fez porque estava premido pela repressão do governo tsarista e porque tinha uma visão nada fatalista de mundo, voltada à intervenção ativa nas lutas sociais, mas também o fez porque sua proposta era, efetivamente, a mais apoiada pelos praktiki (militantes do dia-a-dia, sem papel de direção e em direto contato com a massa operária) e, nela, podemos perceber a maior empolgação com o movimento operário: os trabalhadores estariam preparados e suficientemente organizados para dar um salto em sua articulação, fundar um partido que coordenaria nacionalmente os ataques ao bastião do tsarismo e liderariam todo o povo (narod) russo no processo da revolução (LIH, 2008).

Consequentemente, essas recentes discussões historiográficas são fundamentais para reconfigurar todo o debate que tem sido recentemente travado no âmbito da esquerda (a qual às vezes não consegue se desenvencilhar de preconceitos instaurados pela propaganda antissoviética nascida na Guerra Fria) sobre a teoria do partido político em Lenin.

Contudo, para retornar à avaliação do livro Lenin: teoria e prática revolucionária, não custa reafirmar que essas pequenas ausências são avultadas pelo espírito crítico e criador discernível no decorrer da obra como um todo. Além disso, por se tratar de uma colaboração e de um diálogo que se pretende prolatar no tempo que a tendência é a de que a continuidade das pesquisas sobre Lenin que estão sendo operadas atualmente nos levará ao contato com a nova contribuição historiográfica estadunidense e, consequentemente, será possível apreender cada vez mais eficientemente o contexto de cada texto lenineano e a sua forma de se adaptar teórica e praticamente à realidade circundante. 
Logo, constatamos a evidente pertinência da obra Lenin: teoria e prática revolucionária dentro do contexto atual, vista a relevância de uma leitura criativa de Lenin para a consecução de uma teoria crítica que, preocupada com a libertação dos esfarrapados e das esfarrapadas do mundo, almeja envolver-se ativa e rigorosamente na práxis de libertação dos movimentos populares.

\section{REFERÊNCIAS BIBLIOGRÁFICAS:}

KRITCHEVSKIY, Boris. Ekomonomitcheskaya i polititcheskaya bor'ba v' russkom' rabotchem' dvijenii [Luta econômica e política no movimento operário russo]. Rabotchee Delo, [s.I.], n. 7, p. 1-22, ago. 1899.

LENIN, Vladimir Ilitch. «Kommunizm»: «Jurnal Komunistitcheskogo Internatsionala dlya Stran Yugo-Vostotchnoy Evropy » (Na Nemetskom Yazyke). Vena, Tetradi 1-2, ot 1 Fevralya 1920, do 18-oy, ot Maya 1920. Em: Polnoe Sobranie Sotchineniy. 5. ed. Moscou: Izdatel'stvo Polititcheskoy Literatury, 1980, t. 41, p. 135-137.

LIH, Lars T. Lenin rediscovered: 'What is to be done?' in context. Chicago: Haymarket Books, 2008.

SEGRILLO, Angelo. Historiografia da Revolução Russa: antigas e novas abordagens. Projeto História, São Paulo, n. 41, p. 63-92, dez. de 2010. 